\title{
The Influence of Leadership Roles \& Management Contrivances on Public Service Motivation
}

Mrs. Victoria Ghauri ${ }^{*}$

\begin{tabular}{|c|}
\hline | Received: 09.03.2021 | Accepted: 26.04.2021 | Published: 30.04.2021 \\
\hline *Corresponding author: Mrs. Victoria Ghauri \\
\hline Original Research Article \\
\hline $\begin{array}{l}\text { The topic of this study deals with public service motivation and its relationship with different leadership roles. The } \\
\text { impact of leadership on motivation was not that often examined but by looking at the performances of public } \\
\text { organizations, it seems that there is a relationship between these two variables. According to the different leadership } \\
\text { roles, it would be interesting to have a closer look at the behavior of public managers and their instruments that are } \\
\text { used to enhance motivation of public sector employees. It is problematic to transform the theoretical findings into } \\
\text { practices which managers could use in order to improve their employee's motivation. Furthermore, it is not clear how } \\
\text { and to what extent leadership influences public service motivation. Therefore, it should be concentrated on how this } \\
\text { problem could be solved and which measures have to be taken in order to make it easier for public managers to } \\
\text { influence and enhance the motivation of their staff. First of all, the topic will be introduced with its relevance and } \\
\text { theories and it will be also explained how the research of this study was conducted in order to get the findings that are } \\
\text { needed to conclude and answer the research question. } \\
\text { Keywords: public service motivation, Leadership Roles \& Management, employee's motivation, staff. }\end{array}$ \\
\hline $\begin{array}{l}\text { Copyright }(\text { ) } 2021 \text { The Author(s): This is an open-access article distributed under the terms of the Creative Commons Attribution } 4.0 \text { International } \\
\text { License (CC BY-NC 4.0) which permits unrestricted use, distribution, and reproduction in any medium for non-commercial use provided the original } \\
\text { uthor and source are credited. }\end{array}$ \\
\hline
\end{tabular}

\section{INTRODUCTION}

Employees are an indispensable component in organizations, especially in order to fulfill organizational goals. Therefore, it is necessary that employees perform in a highly efficient and productive way. The importance of people is often taken for granted but it is a necessity to be aware of the fact that organizations are made of people and it is people who provide leadership, stewardship and follower-ship. They also constantly learn new and innovative things that help to support organizations to achieve great goals [1]. Employees are supposed to contribute to the goals of an organization and there is a high significance of understanding how employee's behavior influences an organization.

It is a matter of fact that the performance of employees is generally influenced by their motivation and there are several reasons why motivation is such an important issue in public management. In general, managers have the task of achieving organizational goals by increasing the efficiency and effectiveness of their employees [2]. In order to perform well, employees do not only have to be skilled for their job but they also have to understand what they are required to do [2]. That means that motivation is needed to make employees perform more effectively and efficiently because if the motivation of an employee is equal to zero, even the most talented worker will not be a supportive part of an organization. Another meaningful aspect of motivation is that motivated employees are more committed to the organization they work for and they show less grievance and insubordination which is supportive for the atmosphere at the workplace but also important according to the contact between clients and the employees of an organization [2]. Furthermore, energized and highly motivated workers can reach good performance even though there could be some knowledge gaps [2]. Thus, motivated employees are the greatest asset that an organization can have [2].

It is also important to know which factors have an influence on motivation. In general, the individual characteristics of workers influence their motivation, whereby these characteristics are those which are brought to the work situation like the types of individual needs that are satisfied or not satisfied by the activities that occur with the work in public organizations [3]. Additionally, the job characteristics also affect motivation because it relates to what a 
person is actually doing at work which implies the nature of the job and the collection of tasks that the individual has to do [3]. The characteristics of the work environment do also have an influence on motivation. They can be divided into two categories: immediate work environment characteristics and organizational actions [3]. Organizational actions include the provision of system rewards, provision of individual rewards and the creation of an organizational climate whereby the immediate work environment characteristics relate to transparency of organizational success for employees, personal significance reinforcement or stability of expectations [3]. Additionally, the external environment characteristics also play an important role for public service motivation. They cannot be controlled by the organization directly and they relate to the socionormative, political, demographic, economic and technological changes that also influence the work in public organizations [3].

One important factor according to motivation is leadership. Leadership gives managers the ability to affect the behavior of their employees in an organization. As it was mentioned before, motivated employees are one of the most important results of effective leadership and thus successful managers are also successful leaders because they have great influence on their employees in order to help accomplishing organizational goals [4]. The achievement of organizational goals is not enough in order to keep employees motivated but helping them to accomplish their own personal and career goals is an important part of their motivation [4]. To sum it up, there is a kind of circular flow: the more motivated the employees are, the more effective is the leader and the more effective the leader is, the more motivated are the employees [4]. Even though there is already a basic understanding of the impact that leadership has on motivation, it would be useful to have an even better understanding to have recommendations on how motivation and therefore also performance and goal achievement can be increased. For that reason, the topic of this study concerns the relationship between management and motivation by asking: What do managers in the public sector do to increase the motivation of their staff and how does this change amongst the different roles of leadership?

This issue has been discussed a lot in the past decades and its relevance applies to both, the private and the public sector. In this study, the focus is on the public sector because there has been more research conducted according to the private sector. There are several challenges that public organizations have to face nowadays and that is why it is so important to have well performing and thus highly motivated public sector staff. The aim of this study is to find out about how motivation can be influenced by managerial activity and to what extent these activities change the level of motivation amongst the different leadership roles.

\section{THEORETICAL REVIEW}

Public service motivation can be defined as the predisposition of an individual to respond to motives grounded primarily or uniquely in public institutions and organizations [5]. The main aspect is that the individual is doing well for others and shapes the wellbeing of society [6]. The PSM theory by Perry and Wise shows in an explicit way of what public service motivation 'consists'. The motives that are already mentioned in the definition can be categorized in three different areas: rational, norm-based and affective motives. Rational motives involve actions grounded in individual utility maximization such as the participation in the process of policy formulation in an organization or the commitment to a public program because of personal identification with the program [5]. The normbased motives refer to actions generated by efforts to conform norms like the desire to serve the public interest or the loyalty to duty [5]. In contrast, affective motives refer to impulses of behavior that are grounded in emotional responses to various social contexts like the patriotism of benevolence or the conviction about a program because of its social importance. These kinds of motives exist because of personal attitudes and feelings towards public programs and do not really relate to norms or rationalities. Thus, a variety of these motives might explain public service motivation but it is also important to emphasize that all public employees are really driven by their needs.

Management plays an important role in motivating public workers. Whereby the theory by Perry and Wise gives general ideas about what public service motivation is, it is still not precise in order to find management instruments that enhance motivation. In order to fill this gap, the researcher Yair Re'em conducted a broad set of practical tactics which enhance motivation [2]. This set refers to different categories: rewarding, recognition, feedback, relatedness / commitment, responsibility / autonomy, achievement / challenge / goal setting, career advancement, training, how interesting and important work is, participation, interpersonal relationships, working environment, fairness and work-life balance [2]. Within these categories there are different tactics mentioned that managers can use to have an impact on motivation. For example according to rewarding, Re'em suggests that a manager should give rewards that should be closely tied to behavior and performance and related to feedback, managers should focus more on the future performance than on eventual past mistakes. Besides, it is also important to provide informal recognition to employees because it has a huge impact on their well-being and motivation and it does not cost anything for the manager [2]. Re'em gives a broad range of suggestions what managers can do but according to different leadership roles, there are no explanations at all. For this research the suggestions of Re'em are not broad enough because the aim of this paper relates not only to 
management instruments but also to the leadership roles of managers and how they have an impact on motivation.

\section{RESEARCH QUESTION}

The research question that will be dealt with in this study is 'How do the different leadership roles and the included managerial contrivances influence the level of public service motivation of employees?'. Accordingly, the dependent variable in this research will be 'public sector motivation' and the independent variable will be 'leadership role' but relating to this, the variable 'management instruments' is also examined.

This means in general that there is the focus on the different roles of leadership and their behavior but additionally, the focus will also lie on the managerial practices that are conducted by the different roles of leadership and how they affect public service motivation. So to say, the combination of leadership roles and their practices will be examined and how these two issues affect the level of motivation in the public sector. To avoid misunderstandings, it will be concentrated on the motivation level of public sector workers and not on the motivation of their managers. The sub-questions which will be answered during the further procedure in this study are mostly "What is public sector motivation?' but also 'What is the competing values framework and which leadership roles are included in this theoretical framework?' to get information about the main variables in this study. Furthermore, there will be answers given to the questions 'Which practices are conducted by public managers related to enhance motivation of employees?' and 'How do managers with a high evaluated PSM behave and how do managers which practices conduct managers with a low expected PSM?'. At the end of this study, it will be tried to give an answer to the question 'Did this study get reliable results and what should be respected in future research?'.

As an alternative and a more comprehensive approach, this study will relate to the competing values framework. This model is based on the basic values that highly determine the effective functioning of organizations [7]. Besides, it shows the trade- offs, tensions, contradictions and paradoxes inherent in organizations and their leaders [8] and it comprises two dimensions which demonstrate the competing values or the tensions that characterize organizations in general [8]. One axis represents the continuum between flexibility next to stability or control whereby the other axis articulates the continuum between efficient internal processes like human resources practices or internal control systems versus external positioning related to stakeholders like competitors, clients or customers [8]. Every continuum shows the performance criteria which are opposite from that of the other ending of the continuum: internal versus external orientation on the horizontal axis or flexibility versus stability on the vertical axis [8].

\section{RESEARCH METHOD}

In this study, a cross- sectional research design was used which means that several variables were measured at the same moment in time according to a set of units. In this case, the different units were different managers of public institutions and the variables were the different leadership roles with their subordinate variable, the management instruments.

With the help of literature, the competing values framework and existing management tactics, it will be examined how and if different leadership roles influence the level of motivation in the public sector and which instruments are used within these different roles. With the help of interviews, it will be also examined what managers actually do to enhance motivation and how they influence it by their leadership role. There will also be some impressions of what kind of leadership role which manager conducts and if there is a relationship between the different leadership roles and their practices and the level of motivation.

Seven different public institutions were researched whereby these institutions are mostly located in different areas of the public sector. The study was conducted with public institutions which are located in two cities in Afghanistan. There were two managers interviewed who are directors of administrative agencies of two universities. Another manager that is also part of this study directs an agency in the employment sector whereby there is another manager which guides a department in the health care sector. Additionally, there are two managers who lead different public-law institutions and one who manages an organization which is responsible for self-employed workers. In total, seven managers were surveyed in this study, five men and two women.

This study was conducted as exploratory research which means that the interviews give information in order to get a certain kind of 'in-depth' understanding of the manager's behavior and how they see the motivation of their employees. After conducting the interviews the information was evaluated and analyzed in order to have appropriate findings to get information about an eventual relationship between leadership and motivation.

For getting information about the level of public service motivation, it has to be measured in an appropriate way. Perry developed a measurement scale for public service motivation which implies four dimensions: attraction to policy making, commitment to public interest, compassion and self-sacrifice [9]. With the help of these components, several researchers tried to develop a modified version of it and finally, the 
former 24-item measuring scale by Perry was reduced into a 14-item scale [9]. This change was conducted because Perry's scale was criticized to not represent the rational base of PSM enough. The scale implies three or four statements per dimension, three statements each for the dimensions 'Attraction to policy making' and 'Commitment to the public interest' and four statements each for the dimensions 'Compassion' and 'Selfsacrifice' [9].

In former research, civil servants who evaluated the statements had to respond with a 5-point Likert-type scale from one to five where one means 'strong disagreement' and five 'strong agreement' [9]. Some examples of the statements are 'I am interested in making public programs that are beneficial for my country or the community I belong to' or 'Meaningful public service is very important to me' [9].

Within this study, some aspects of the explained research were overtaken to get to know how managers see the level of motivation of their employees. They had to fill out a questionnaire with ten statements that relate to the four dimensions of Perry's measurement scale. Related to the dimension 'Attraction to policy making', there were two statements given: 'My employees engage a lot in public programs.' and 'My employees feel greatly satisfied if they see that people get benefits from the public program that they have been involved in.'. Additionally, there were three statements that should be ranked according to the dimension of 'Commitment to public interest'. These statements were 'Public service in general is very important to my workers.', 'The employees see a higher importance in public service being a civil duty than in their own interests.' and 'For my employees, it matters a lot if public official do what is best for the whole community.'. The third dimension 'Compassion' was evaluated with the statements 'My employees show some kind of a passion for their employment.' and 'During the working hours, my employees are not that enthusiastic'. Sometimes, negative statements were given in order to see if the managers fill out the questionnaire attentively and to check if they give the appropriate attention to the statements. Finally, three statements to the last dimension 'Self-sacrifice' were also responded: 'The willingness of my employees to sacrifice for the common good, is not high.', 'The workers serving other citizens would give them a good feeling even if they would not be paid for it.' and 'Making a difference in society means more to my employees than personal achievements.'. These statements were ranked by the different managers from one to five to give information about their impressions of public service motivation of their workers.

\section{DATA ANALYSIS}

This study concentrated on finding data and information about the level of public service motivation, different leadership roles of managers relating to the competing values framework and also about the management instruments which are used in each role.

The survey contained two sections: the first section included ten different statements which relate to the four dimensions of public service motivation. These statements were evaluated by the managers to show their impressions of the staff's motivation. With the use of a 5-point Likert-type scale, they evaluated motivation, whereby one was the position for 'I do not agree' and five was the position for 'I totally agree'. The rankings of the statements were then summed up and shown with a 'traffic light color' for the table which shows how they see their employee's motivation relating to that dimension. The 'green' value indicates that the manager has a quite positive impression about the PSM level, 'blue' means that the impression is neither positive nor negative, it seems to be quite neutral then. The 'red' value shows that the manager does not think that employees are motivated in this dimension or that there is only a little less motivation.

The second exercise of the survey was related to the leadership roles and the management practices within these roles. Eight different boxes were part of the survey whereby each box had a number of statements related to a leadership role from the competing values framework. The managers chose three out of eight boxes to show which skills and characteristics they think are the most important ones and with which they identify. The first two boxes in the survey were related to the 'create' dimension of the competing values framework. Box no. 1 included the key words 'flexibility, creativity, change' and referred to the leadership role of the 'Innovator'. The second box in the same dimension contained the words 'power-base, negotiating, presentation of new ideas' and showed therefore the skills of the 'Broker' role. With respect to the second dimension of the competing values framework, the 'compete' dimension, the third box included the key aspects 'productivity, time and stress management, productive work environment' and therefore clearly represented the 'Producer' role. Within box no. 4 the key issues were 'visionary leadership, efficiency and organization' and they corresponded to the role of the 'Director'. According to the 'control' dimension of the CVF, the fifth box which referenced to the 'Coordinator' role, included the issues 'managing projects, delegation of different functions, job design'. The second role of this dimension, the 'Monitor' role is distinguished by the key aspects of the sixth box which were 'monitoring personal management, control, clear (hierarchic) roles and structures). Referring to the 'collaborate' dimension, the roles of the 'Facilitator' 
and the 'Mentor' were also transformed into boxes in the survey. The seventh box which related to the 'Facilitator' included the aspects of 'teamwork, decentralized decision-making, conflict management' whereby the eight and last box, referring to the 'Monitor', included 'communication, understanding, common values and norms'.

In the interviews, the questions that were asked related to the chosen boxes in the survey because the survey gave a first impression which leadership roles the manager prefers but it was also necessary to get information about the particular instruments which the managers conduct. Therefore, the questions in the interview were created in order to get information about the instruments and to understand what they are actually doing in their position.

The analysis process of the independent variable 'level of public service motivation' started with evaluating the data given in the survey. The managers had the possibility to rank the different statements from one to five whereby one meant 'I do not agree' and five was the position for 'I totally do not agree'. There were ten statements, two relating to 'Attraction to policy making' and three each relating to 'Commitment to the public interest', 'Compassion' and 'Self-sacrifice'. The ranks that the managers gave to the statements were evaluated and analyzed with the help of a table and three different colors which relate to the traffic lights system. The color green symbolizes that the manager has the impression that PSM in the specific topic is positive and strongly existing whereby the color blue means that the motivation level is from his/her point of view quite neutral. The red color shows that the manager thinks his/her employees do not have motivation in this area at all or at least only a bit.

To get an overview about the PSM results, a chart was conducted which shows the four dimensions and the manager's positions. With the help of this chart it is possible to see the general or overall degree of public service motivation that is seen from the eyes of the manager. If the column of one manager contains more green words than blue or red words, then the general impression of the manager is quite positive, if blue or red are overbalanced in one column, then it is visible that the manager's impression is not that positive. Furthermore, this table shows which dimension has the most positive PSM evaluations and which dimension is seen more negatively by the managers.
For analyzing the dependent variable 'leadership roles', there was also a chart made to get a general overview of which leadership roles were chosen more often or which leadership roles were not chosen at all. The horizontal row at the very top of the chart contains the eight different leadership roles of the competing values framework: the Innovator, Broker, Producer, Director, Coordinator, Monitor, Facilitator and Mentor. Furthermore, each row relates to one of the seven managers that filled out the surveys and that were interviewed. Then it was evaluated which three leadership roles were chosen by which manager and in the respective column, an ' $\mathrm{X}$ ' was made. This method made it possible to show which leadership role was chosen mostly and which roles were chosen by the different managers.

In order to analyze the interviews, the procedure was more time consuming and costly in terms of labor. First of all, all interviews were transliterated in order to get the information of the conversations in a truthful way and to have the possibility of referring to them if it is necessary. Then, the interview transcripts were coded manually with the help of different colors which marked statements in the interview that related to certain variables. Because of that, it was easier to see which variables were mentioned how often in an interview. The next step was the creation of a big table containing 24 variables which were all mentioned in the interviews with the managers and which relate to the leadership roles of the competing values framework. Therefore, all variables were ranked with the help of a special scale that was conducted. It went from ' ++ ' which shows that there is a high importance of this variable until '- -'which indicates that the manager sees no significance of this variable at all. If the manager is not really sure of how to evaluate this variable, there was a ' 0 ' given. With the help of this table, the interviews were better internalized and it gives a general overview about which variables are preferred by each manager.

\section{FINDINGS AND DISCUSSION 1. Public Service Motivation}

Four different categories were used to evaluate the staff's motivation from the manager's points of view. The summary of the findings which regard to the four dimensions can be found in the next table. Below we will elaborate on this table. 
Victoria Ghauri., Sch J Arts Humanit Soc Sci, Apr, 2021; 9(4): 117-129

Table-1: Results of the manager's evaluations on PSMs

\begin{tabular}{|l|l|l|l|l|}
\hline & Attraction to policy making & Commitment to the public interest & Compassion & Self-sacrifice \\
\hline Manager A & Green & Blue & Green & Blue \\
\hline Manager B & Green & Green & Green & Blue \\
\hline Manager C & Green / Blue & Green & Blue & Red \\
\hline Manager D & Green / Blue & Green & Blue & Blue \\
\hline Manager E & Green / Blue & Green & Green / Blue & Blue \\
\hline Manager F & Blue & Green & Blue & Green \\
\hline Manager G & Green / Blue & Blue & Blue & Red / Blue \\
\hline
\end{tabular}

The first dimension that should be evaluated was 'Attraction to policy making'. Two statements were chosen: 1) 'My employees really engage in participating in public programs.' and 2)'Seeing people get benefits from the public program my employees have been deeply involved in, brings them a great deal of satisfaction.' Because we used multiple statements for measuring this dimension the interpretation could not always be straightforward. Therefore, in some cases there are 'combinations of colors'. The outcomes show that six of the seven managers have (inter alia) the 'green' value in their columns. Four of them have a combination of the 'green' and the 'blue' value and only one manager has 'blue' as the single value in this dimension. Those six managers who have 'green' values in their columns believe that their staff is attracted to policy making. For two managers this is absolutely clear, while four managers have some small reservation. There is only one manager who has some doubts about his staff in this dimension. All in all it is clear that with respect to this dimension of PSM that almost all of the managers in this study hold the belief that their staff is attracted to policy making. Another dimension that was evaluated in the survey was 'Commitment to the Public interest' which included three statements that have been appraised: 1) 'Public service is very important to my employees.', 2) 'My workers see a higher importance in public service as their civic duty than in their own interests.' and 3) 'My employees prefer seeing public officials do what is best for the whole community, even if it harms their interests.' The results indicate that five of seven managers have 'green' as the single value in this dimension and only two managers have 'blue' as the single value which means that five managers think that their employees show a high degree of commitment to the public interest and that they have a high level of motivation in this dimension. Two managers have the impression that their staff is not that enthusiastic and motivated in this dimension, they seem to have some doubts about motivation. In general, this is the dimension with the most positive results of motivation and it indicates that almost all of the managers think that their staff is highly motivated in commitment to the public interest.

The third dimension of PSM was 'Compassion' which included again only two statements: 1) 'The employees show a certain kind of passion in their occupation.' and 2) 'During working hours, the staff is not that enthusiastic.' Within this dimension, only two out of seven managers chose 'green' as a single value and only one manager has 'green' in combination with 'blue'. Furthermore, four managers chose 'blue' as their single value. Compared to the other dimensions, this one shows a quite low amount of 'green' values which means that only two managers are totally convinced about their staff being compassioned at work. Most of the managers have doubts about their employees having motivation in compassion whereby one of them is somewhere 'in between'. This means there are some little reservations of this manager towards his staff's motivation. In total, this dimension indicates that most of the managers have some disbelief against the compassion of their staff in doing work in the public service and only two think that there is compassion.

The last dimension 'Self-sacrifice' contains the statements: 1) 'Serving other citizens give my workers a good feeling even if no one would paid them for it.', 2) 'My employees are not really prepared to make enormous sacrifices for the good of society.' and 3) 'Making a difference in society means more to my staff than personal achievements.'. There is only one manager who has a 'green' value in this dimension, whereby the most chosen value is 'blue' which was taken by three managers as a single value. Two managers have 'blue' as a value combination, once with 'green' and once with 'red'. One of the managers even has the 'red' value in this dimension which is the only one amongst all dimensions. Most of the managers in this dimension have doubts about the self-sacrifice of their employees, whereby one also thinks that there is a positive tendency of his staff but another one sees an even more negative tendency. Only the one manager with the 'green' value thinks that his staff has a high motivation in self-sacrifice and another one even has quite negative impressions about that and evaluates the self-sacrifice as almost not existing. Thus, in this dimension of PSM it is clear that almost all of the managers have doubts of their staff being self-sacrificed and even one is quite sure that there is no amount of self-sacrifice.

The overall impression of PSM that can be received is that most of the managers chose the 'blue' value which indicates that they are in general thinking 
positive about their staff's level of motivation, but there are also some doubts about it. The 'blue' value was voted 17 times either as a single value or in a value combination and therefore it can be said that the position of the managers towards public service motivation is quite neutral, not positive but also not negative at all. The 'green' value that shows a positive impression of the managers was chosen 15 times in total. This is a bit less than the 'blue' value but it implements that the tendency of the manager's impressions has a direction towards the positive attitude. Even though there are some more 'blue' values, the 'green' values indicate a general positive attitude of most of the managers in this study towards PSM. This impression is also supported by the fact that the 'red' value which indicates a negative impression was only chosen twice in the whole study. This shows that almost no manager had a very negative impression of employee's motivation.

\section{Leadership Roles}

The managers were asked to rank three out of eight boxes with which he/she identifies most with and which he/she thinks contain the most important issues based on leadership roles. Each box had a number of statements related to a particular leadership role from the competing values framework. The labels of the leadership roles such as 'Mentor' or 'Broker' were not mentioned, implying that the manager could really concentrate on the issues inside the box without being distracted from 'fancy labels'. The outcome of this exercise in which the managers chose the leadership roles can be found in the next table.

Table-2: Overview of leadership roles and their occurrences

\begin{tabular}{|l|l|l|l|l|l|l|l|l|}
\hline & \multicolumn{2}{|l|}{ Create } & \multicolumn{2}{l|}{ Compete } & \multicolumn{2}{l|}{ Control } & \multicolumn{2}{l|}{ Collaborate } \\
\cline { 2 - 9 } & Innovator & Broker & Producer & Director & Coordinator & Monitor & Facilitator & Mentor \\
\hline Manager A & & & $\mathrm{X}$ & & & & $\mathrm{X}$ & $\mathrm{X}$ \\
\hline Manager B & & & & $\mathrm{X}$ & & $\mathrm{X}$ & & $\mathrm{X}$ \\
\hline Manager C & & & $\mathrm{X}$ & $\mathrm{X}$ & & $\mathrm{X}$ & & \\
\hline Manager D & & & & & $\mathrm{X}$ & & $\mathrm{X}$ & $\mathrm{X}$ \\
\hline Manager E & $\mathrm{X}$ & & & & & & $\mathrm{X}$ & $\mathrm{X}$ \\
\hline Manager F & & & & & $\mathrm{X}$ & & $\mathrm{X}$ & $\mathrm{X}$ \\
\hline Manager G & & & $\mathrm{X}$ & $\mathrm{X}$ & $\mathrm{X}$ & & & \\
\hline
\end{tabular}

Leadership roles of the 'collaborate' dimension were chosen by most of the managers: five out of seven managers considered to the 'Mentor' role and four of them considered to the 'Facilitator' role. In contrast, the leadership roles which are included within the 'create' dimension are roles which got the fewest 'votes' by the managers. This means in detail, the 'Innovator' role was only chosen by one manager and the 'Broker' role was not chosen at all. The 'compete' dimension which included the 'Producer' and the 'Director' role, is the dimension which got the second most votes: both leadership roles were voted by three managers. The results for the 'control' dimension were quite similar to the results of the 'compete' dimension. The 'Coordinator' was chosen three times, the 'Monitor' role only twice. Thus, the managers in general valued the key aspects of the 'Facilitator' and the 'Mentor' role most, whereby the characteristics of the 'Innovator' and 'Broker' were not really favored by them.

Another aspect which attracts attention is the fact that leadership roles which 'relate' to each other because they are located in the same dimension of the competing values framework and also have the same or similar numbers of rankings by the managers. In the 'create' dimension, the roles have one and zero votes, the 'control' dimension roles have three and two and finally, the 'collaborate' dimension has four and five votes of the managers. In the 'compete' dimension, even both leadership roles have exactly the same numbers of votes: each role has three.

By ranking the leadership roles, the managers also gave their preferences towards them. This means that the role that was chosen firstly is also the most important one or the one they mostly identify with. If the first preferences of all managers are compared it is possible to see which leadership role is preferred in general and if there is maybe another leadership role which was not chosen that often but maybe has more first preferences than other roles. The following table gives an overview of the leadership roles and their preferences given by each manager. 
Table-3: Summary of the manager's preferences in leadership roles

\begin{tabular}{|l|l|l|l|}
\hline & First Preference & Second Preference & Third Preference \\
\hline Manager A & 'Mentor' & 'Producer' & 'Facilitator' \\
\hline Manager B & 'Director' & 'Mentor' & 'Monitor' \\
\hline Manager C & 'Producer' & 'Director' & 'Monitor' \\
\hline Manager D & 'Mentor' & 'Facilitator' & 'Coordinator' \\
\hline Manager E & 'Innovator' & 'Facilitator' & 'Mentor' \\
\hline Manager F & 'Mentor' & 'Coordinator' & 'Facilitator' \\
\hline Manager G & 'Producer' & 'Director' & 'Coordinator' \\
\hline
\end{tabular}

Three out of seven managers chose the 'Mentor' role as their first preference, followed by two managers who chose the 'Producer'. The 'Director' and the 'Innovator' were chosen once. This shows that the 'Mentor' is the most dominant role of the managers because in comparison to the other leadership roles it was chosen by most of the managers as the first preference. This fact supports the former impression that the 'Mentor' role is the most 'popular' one because it is also the most chosen role. It is surprising that the 'Facilitator' role which is the second most chosen role in the whole study was not chosen at all as a first preference. In contrast, the 'Producer' was only chosen three times in the whole study and twice chosen by managers as their first preference. These results give the impression that the 'Producer' and not the 'Facilitator' role seems to be the second most important role after the 'Mentor'. But all in all it does not seem to be enough to only compare the first preferences or the amount of votes that every role received in order to know which roles are more favored in this study.

Another way of interpreting the results and of getting a recessed impression of the manager's preferences is to attach weights to the different rankings. This means that every role which is a first preference gets three points per choice, every second preference gets two points and every role which is a third preference gets one. All of the leadership roles have then a certain number of points that show which roles have the highest preferences by the managers. But it is also important to include the numbers of votes which every role received in this study because these numbers show how often a leadership role was voted and if it was generally favored by the managers. The preference points only show how important or significant a role is to the managers who voted it. Thus, both approaches should be considered by summarizing the number of votes in this study and also the number of preference points which each role received. Then a total score can be created which makes it possible to create a ranking list of all leadership roles.

It could be possible that there is a leadership role which was chosen only three times but has a high score of preferences and it is also possible that a role which was chosen very often only has a low score of preference points. Therefore it will be interesting to see if the evaluation of preferences supports the first assumption that the 'Mentor' and the 'Facilitator' role are still the favored roles in this study. The given preferences as well as the amounts of preference points and votes and the total scores can be found in the table below.

Table-4: Final results referred to leadership roles

\begin{tabular}{|c|c|c|c|c|}
\hline & Preference & Preference Points & Votes in general & Total Points \\
\hline Mentor & $\begin{array}{l}1^{\text {st }} \text { Preference: } 3 \\
2^{\text {nd }} \text { Preference: } 1 \\
3^{\text {rd }} \text { Preference: } 1\end{array}$ & 12 & 5 & 17 \\
\hline Producer & $\begin{array}{l}1^{\text {st }} \text { Preference: } 2 \\
2^{\text {nd }} \text { Preference: } 1 \\
3^{\text {rd }} \text { Preference: } 0\end{array}$ & 8 & 3 & 11 \\
\hline Director & $\begin{array}{l}1^{\text {st }} \text { Preference: } 1 \\
2^{\text {nd }} \text { Preference: } 2 \\
3^{\text {rd }} \text { Preference: } 0\end{array}$ & 7 & 3 & 10 \\
\hline Facilitator & $\begin{array}{l}1^{\text {st }} \text { Preference: } 0 \\
2^{\text {nd }} \text { Preference: } 2 \\
3^{\text {rd }} \text { Preference: } 2\end{array}$ & 6 & 4 & 10 \\
\hline Coordinator & $\begin{array}{l}1^{\text {st }} \text { Preference: } 0 \\
2^{\text {nd }} \text { Preference: } 1 \\
3^{\text {rd }} \text { Preference: } 2\end{array}$ & 4 & 3 & 7 \\
\hline Monitor & $\begin{array}{l}1^{\text {st }} \text { Preference: } 0 \\
2^{\text {nd }} \text { Preference: } 0 \\
3^{\text {rd }} \text { Preference: } 2\end{array}$ & 2 & 2 & 4 \\
\hline Innovator & $\begin{array}{l}1^{\text {st }} \text { Preference: } 1 \\
2^{\text {nd }} \text { Preference: } 0 \\
3^{\text {rd }} \text { Preference: } 0\end{array}$ & 3 & 1 & 4 \\
\hline Broker & -- & --- & -- & -- \\
\hline
\end{tabular}




\section{a) The 'Mentor'}

The role which comes in first is actually the 'Mentor' role. This role received by far the highest score of preference points as well as the highest score of votes in general, which means that many managers favored this role in the study but also that they all see a high importance and significance of this role.

Therefore, their management instruments mostly relate to his role and the five managers which chose this leadership role showed some similarities in their management practices.

All managers who chose the 'Mentor' leadership role emphasized that communication is a fundamental value in their organizations. For that reason team meetings are held and some managers emphasized that they convene meetings daily with all employees and other managers claimed that once a week a team meeting is conducted. In general, they all use communication in order to be always up-to-date and to be informed about changes. Also a general understanding of each other is an important issue to all managers who chose the 'Mentor' role. They all described themselves as pretty understanding towards their employees regardless of the situation the understanding was needed. Some managers described that relating to special cigarette or coffee breaks hey are quite flexible by accepting them as well as flexible working times if this is requested by the workers. But all of them also emphasized in matters of understanding that they also expect the employees to work on their tasks adequately and that deadlines have to be obeyed. As long as this is considered, the managers have a big understanding towards their employees.

\section{b) The 'Producer'}

The 'Producer' has the second highest total score in the table which is at the first sight a quite surprising results because it was only chosen by three managers. Two of the three managers that chose the 'Producer' see this role as their first preference which means that these managers showed a high importance of this role. Therefore, the 'Producer' has the second highest amount of preference points. In general, it indicates that the three managers also see a high significance in the management practices of this role and use them a lot in their daily work life.

A fundamental aspect in the 'Producer' role is productivity and a productive work environment. All three managers see productivity as crucial and do different things for fostering it. One of them emphasizes that the formulation of common organizational goals and the communication about it is very important as well as providing software programs which support the employees. Another manager claims that there are periodic times of the year in which his employees are not that productive because the workload increases. In these difficult situations, he fosters the productivity by showing his presence and providing good basic conditions, for example in summer he provides some ventilators or ice cream but also some additional employees are hired to share the workload amongst more people.

\section{c) The 'Facilitator' and the 'Director'}

These leadership roles which are on the third and fourth position in table are the 'Facilitator' and the 'Director' role and both have the same total score of 10 . Not only the total score but also the numbers of preference points and votes are quite similar according to these two roles, they only differ by one point in each category. The 'Director' shows a little higher amount of preference than the 'Facilitator' but this role has one more vote in general than the 'Director'. This means that even though the 'Director' has one less vote than the 'Facilitator' but one more according to the preference points, the three managers who chose the 'Director' role see a relatively high significance in this role and its focuses. The 'Facilitator' was chosen by one more manager which indicates that it is in general a bit more favored than the 'Director' but the amount of preference points is a bit lower than the amount of the 'Director'. Therefore, the four managers who chose the 'Facilitator' do not see such a high importance of the role as the three managers who chose the 'Director' do. Although they have the same total score in the ranking list, the management practices of both leadership roles concentrate on different things.

Four of seven managers chose the 'Facilitator' role which inter alia includes the importance of teamwork. All of them support the assumption of teamwork being to some extent an important issue in their organizations. Some of them explain that if employees are absent because of illnesses or they are on vacation, it is only possible with teamwork to get the whole workload of the department done. This means that more than just one person needs to be able to do different tasks so that one task can be shared by many employees if this is necessary. The manager's task related to teamwork is mostly to delegate it from the outside and to provide an unobstructed working procedure and not being involved actively. Only one manager claimed that teamwork is fundamental in his organization because every team in every department is an interdisciplinary team of different employees doing all different tasks and therefore the significance of teamwork is even higher in this organization compared to the others. With respect to decision making processes in the different organizations, all managers set value on decentralization. Even though the single procedures differ a bit, the general processes are quite similar in all organizations. In situations, in which a decision needs to be made or a task has to be done, the managers activate it in the team meetings and encourage their workers to give some suggestions. Based on these suggestions, the 'result' is designed by the employees 
as long as the manager does not have any objections or recommendations for improvement. Important in this process is that the managers gives a lot of autonomy to the colleagues but they always have a look over their shoulders. Finally, the draft of the result is presented to the managers and in the end they are the only ones that have the competence to 'make' the final decision but this is based on the work of the employees.

\section{d) The 'Coordinator'}

The fifth position in the ranking list has the 'Coordinator' role with a total score of seven. Compared to the other roles, the 'Coordinator' had no really satisfactory results in this study. The 'Mentor' role in the first position has even ten points more than the 'Coordinator'. The amount of preference points and votes in general do not really differ from each other, there is only one point distinction. In the preference part, this role has one point more than the amount of general votes which indicates that the three managers who chose the 'Coordinator' also see a certain degree of importance in this role. The amount of preference point is indeed not that high as in the four superordinate positions but in relation to the number of votes that this role received it is quite satisfying. Therefore, the three managers which chose the 'Director' see not a really high importance in conducting the practices of this role but they relate to this role to some extent in their management practices.

The management of projects is one of the fundamental issues in this role. All managers indicated that projects are part of the daily work life, to some managers more and to some less. One of them emphasized that project management is a main tasks in her organization and that her department mostly deals with the introduction of new projects. According to that, she delegates her employees and counts on their autonomous work behavior to plan and design the projects. Another manager examines that projects are also a part of the work life but are not that important in this organization. Mostly, projects are conducted with external partners who do not work in his organization but there are also some projects which are arranged by his employees. He sees his task in delegating these procedures from the outside and letting his employees work on that. The third manager in this section claims that projects are not that often the case in his daily work life but in his organization, an operational healthcare management should be introduced soon.

\section{e) The 'Monitor' and the 'Innovator'}

The lowest amount of total scores has two roles, the 'Monitor' and the 'Innovator' role. Both have a total score of four but the compositions of these scores are quite different. The 'Monitor' was chosen twice and has the same value as amount of preference points. This means that the preference of the managers who chose this role is very neutral, they consider this role and relate to a low extent to it, but they do not seem to have a high preference for it because it was twice chosen as a third preference. Therefore, the management practices included in the 'Monitor' role are considered but do not play a very important role. In contrast to that, the 'Innovator' role was only chosen once by a manager but this was his highest preference which indicates that he totally relates to this role and sees a high significance of it in his work life. This also indicates that the practices of this manager relate to a high extent to the practices which are part of the 'Innovator' role.

A typical issue which is related to the 'Monitor' role is a clear and hierarchical structure within the organization. One manager examined that because of a fusion of his company with another one some years ago, clear roles and structures were determined and therefore all employees know their function and their role in the organization. It is also necessary that everyone knows the focus of his function and in order to provide this it is important to deal transparently with it so that all information about the roles and structured are available for everyone. The other manager also explains that maintaining the hierarchy of her company is needed because otherwise it would not be clear who has which responsibilities and who has which competences. With regard to this, it should also be provided that employees are not overstrained. The task of the manager is to provide that the hierarchy is maintained by providing rules and structures to her subordinate departments. She also examines that $90 \%$ of her employees wish to have clear roles and requirements in order to know what they are allowed to do. Control is another aspect which is part of this leadership role. In order to provide control in his organization, one of the managers claims that he has clear requirements and demands according to his employees and that they are discussed in a meeting at the end of each year so that the employee is informed about them. In these meetings it is discussed which organizational goals should be achieved and the results of the employees can always be apprehended and checked in the controlling department of the organization.

Only one manager chose the role of the 'Innovator'. According to flexibility which is included in this role, he explains that his agency is quite flexible, even though they have to obey a strict legal framework. But how special things are regulated for example how employees are applied or where there are the focuses in their work, this is up to him and his colleagues.

Evaluating the findings of this study, it is obvious that the 'Mentor' role is the most favored role amongst all managers. But this result should also be pulled together with the results of PSM of the different managers and their choices of leadership roles in this study. The table below shows the hierarchy of managers according to their estimated PSM level of their staff and 
Table-5: Confrontation of PSM results and preferred leadership roles PSM hierarchy of managers Choice of leadership roles with preference

\begin{tabular}{|l|l|l|}
\hline \multirow{4}{|l}{ 1. Manager B } & 1. Director 2. Mentor 3. Monitor \\
\hline 2. Manager D & 1. Mentor 2. Facilitator 3. Coordinator \\
\hline $\begin{array}{l}\text { 3. Manager A \& } \\
\text { Manager E }\end{array}$ & $\begin{array}{l}\text { 1. Mentor 2. Producer 3. Facilitator } \\
\text { 1. Innovator 2. Facilitator 3. Mentor }\end{array}$ \\
\hline & 4. Manager F & 1. Mentor 2. Coordinator 3. Facilitator \\
\hline 5.Manager C & 1. Producer 2.Director 3. Monitor \\
\hline 6. Manager G & 1. Producer 2.Director 3. Coordinator \\
\hline
\end{tabular}

The managers within the first three positions of the PSM hierarchy all chose the 'Mentor' role, two of them even as their first preference. The last two positions in the PSM hierarchy did not chose the 'Mentor' at all which means that these positions with the most negative expected PSM level see no relevance in this role. One could get the impression that there is a positive relationship between the 'Mentor' role and a high expected level of public service motivation because in the table it can be seen that all managers with a positive or high evaluation of their staff's motivation relate to the 'Mentor' role. Furthermore, this would imply that the instruments that are used in this role and relate to communication, common values and norms but also to understanding lead to higher motivation. This impression gets supported by the fact that the managers with the most negative impression of PSM do not use see any significance in using instruments which relate to the 'Monitor' role. Therefore, the first hypothesis that can be derived is:

H1: 'The 'Mentor' role and the included management instruments relating to communication, understanding and common values lead to a higher level of public service motivation.'

The 'Producer' was chosen as the second favored leadership role in this study. Because of that we could come to the conclusion that the PSM levels of managers who have a high preference in this role are also quite positive, like it was with the 'Mentor' role. But by looking at the table we can see that the 'Producer' was mostly chosen by these managers who show the lowest PSM level and they chose it even as their first preference. In contrast to that, within the first three positions in the table, this role was only chosen once. This means that the managers with the lowest PSM levels see a very high significance of this role and strongly obtain to productivity. Relating to that, we can suppose that there is a negative relationship between managers that relate to the 'Producer' role and use mainly instruments which relate to productivity and the level of PSM that these managers have. The second hypothesis of this study is:

H2: 'The 'Producer' role and the included instruments which relate mainly to productivity lead to a lower level of PSM.'
If we have a look at the combinations of leadership roles that were chosen by the managers we see that the 'Mentor' and the 'Facilitator' role are often chosen in combination by a manager. Four of seven managers chose the 'Mentor' as well as the 'Facilitator'. These two roles are part of the 'collaborate' dimension in the competing values framework and therefore they relate to each other. If we compare the other results of the leaderships chosen, we also see that the 'Producer' and the 'Director' were also chosen together by two managers. These two roles are also located in one dimension, namely the 'compete' dimension. Related to that, there are no other combinations of roles which are in the same dimension, the 'Coordinator' was never chosen together with the 'Monitor' by one manager and the 'Innovator' was also never chosen with the 'Broker'. In the table it can be noticed that the combinations of 'Mentor' and 'Facilitator' are chosen by the first four positions in the PSM hierarchy which means that managers with a high expected PSM level chose this combination, whereby in contrast the combination of the 'Producer' and the 'Director' was chosen by the two managers who have the lowest level of PSM. This could mean that the 'Mentor' and the 'Producer' role are supported in their effect on public service motivation by their related roles of their dimension and that the roles of one dimension strengthen each other. Therefore, we come to the hypothesis:

H3: 'Leadership roles of the competing values framework which are located in the same dimension have similar effects on public service motivation.'

The last two positions in the PSM hierarchy show the managers with the fewest amounts of PSM levels. The group of managers which was part of this study consisted of five men and two women. By analyzing the different persons and their expected PSM levels it can be recognized that the managers which show the lowest amount of PSM are the two women which were part of the study. Within the interviews they often referred to working productively and to concentrate on efficiency. But from their points of view and compared to the men of this study, these female managers expected the lowest amount of PSM. The men in this study all related to a certain extent mostly to communication, teamwork, conflict management and 
decentralized decision making whereby the ladies mostly talked about efficiency, visionary leadership, productivity and organization. There could be different causes for the fact that the women mostly concentrate on these issues and not the male managers. One reason could be that women in management positions often have to be more authoritarian in order to be taken seriously and therefore they concentrate more on structure, organization and that the outcomes of the organizations are appropriate. Furthermore it could be the case that the female managers have a more skeptical view and are maybe more realistic than their male colleagues who maybe have a tendency of 'embellishing' the reality and maybe they see their staff's motivation more positive as it really is. But despite these speculations, it seems as if there are differences between male and female implementations of management in general and maybe also different perceptions of motivation. Thus, we come to the hypothesis:

H4: 'There might be differences between the male and female implementation of leadership roles.'

\section{CONCLUSION AND SUGGESTION}

Referring to the main research question of this study: 'How do the different leadership roles and the included managerial contrivances influence the level of public service motivation of employees?, the results are not that explicit. The relationship of the variables 'leadership roles' and 'public service motivation' seems to exist somehow but it is not really clear if there is a real negative or positive relationship.

It is unambiguous that the 'Mentor' role was mostly chosen by managers who evaluated a higher level of PSM. All managers of the first three positions chose amongst others the 'Mentor' role and this leadership role was furthermore the most chosen one in this study. This fact shows that there somehow seems to be a connection between managers who see a high significance in the 'Mentor' role and their high expected level of public service motivation. Another supportive argument for this assumption is the fact that the two managers with the lowest expected level of motivation both do not have the 'Mentor' role in their preferences at all. In the previous parts of this thesis it was also discussed that the 'Producer' and the 'Director' role seem to have a negative impact on public service motivation because they were less chosen by the managers with higher PSM levels and were always the first and second preference of the managers with the lowest evaluated PSM.

By looking more closely at the table it can be noticed that even though these two facts referring to the 'Mentor', 'Producer' and 'Director' role are right, it is also a matter of fact that the roles can be found in the preferences of managers who have a high expected level of PSM. For example, the managers who shows the highest level of PSM has the 'Director' role as the first preference and also one manager who is placed at the third position chose the 'Producer' as the second preference. Furthermore, one manager who seems to have not that high level of PSM compared to the others, chose the 'Mentor' and the 'Facilitator' as first and second preference. This indicates that even though there is a tendency of managers who chose the 'Mentor' role and have a high level of PSM, all leadership roles were chosen by all managers which means it is difficult to determine a certain pattern in these results.

Additionally, it is not really possible to answer the question 'how' the different leadership roles and the managerial instruments influence public service motivation. The managers explained a lot about procedures and practices in the interviews and there were some of the practices were mentioned often by managers and many of them related to the role characteristics of the 'Mentor'. But we do not really know how and which exact management instruments lead to high public service motivation. In this study, we get several ideas of which instruments are used by which managers and if they have a high expected level of PSM or not, but the results do not show that there are one or two specific practices that definitely enhance motivation.

All in all we can indicate that there seems to be a correlation with a positive tendency between especially the 'Mentor' role of the competing values framework and high public service motivation and maybe also a correlation with a negative tendency according to the 'Producer' and the 'Director' role and PSM. But in general, it cannot be clearly examined that there is a positive or negative relationship between leadership roles and public service motivation. What is a definite finding and result of this study is that it can be rejected that there is not relationship between the two variables at all. If this was the case, then no relationship and not tendencies could be examined.

\section{REFERENCES}

1. Warigon, Slemo D. Managing people for organizational success. In: The IT Metrics\& Productivity Institute. 2012. Retrieved from: https://www.itmpi.org/Portals/10/PDF/WarigonPeo ple.pdf.

2. Re'em Y. Motivating Public Sector Employees. Hertie School of Governance- Working Papers, Nr. 60. 2011.

3. Perry J, Porter L. Factors Affecting the Context for Motivation in Public Organizations. The Academy of Management Review, 1982;7(1):89-98.

4. Naile I, Selesho JM. The role of leadership in employee motivation. Mediterranean Journal of Social Sciences. 2014 Mar 5;5(3):175-182.

5. Perry JL, Wise LR. The motivational bases of public service. Public administration review. 1990 May 1:367-73. 
6. Vandenabeele W. Explaining public service motivation: The role of leadership and basic needs satisfaction. Review of Public Personnel Administration. 2014 Jun;34(2):153-73.

7. Baráth T. Effectiveness in Public Education: Models and Aspects of Leadership. In: Hungarian Institute for Educational Research and Development. 2009. Retrieved from: http://ofi.hu/effectiveness-public-educationmodels-and-aspects-leadership.

8. Lavine M. Paradoxical leadership and the competing values framework. The Journal of Applied Behavioral Science. 2014 Jun;50(2):189205.

9. Kim S. Revising Perry's measurement scale of public service motivation. The American Review of Public Administration. 2009 Mar;39(2):149-63. 